\title{
A CLINICOPATHOLOGICAL STUDY OF LACRIMAL FOSSA LESIONS AT A TERTIARY CARE CENTRE
}

\author{
Hemalatha Krishnamurthy¹, Manjula Devi N², Venkategowda H. T33, Archana $S^{4}$, Amulya Padmini H. M5, Padmini $S^{6}$, Aayesha Fatima \\ Shwetha G. $R^{8}$
}

\author{
${ }^{1}$ Associate Professor, Department of Ophthalmology, MMC and RI, Mysore. \\ ${ }^{2}$ Associate Professor, Department of Ophthalmology, MMC and RI, Mysore. \\ ${ }^{3}$ Retired Professor and HOD, Department of Ophthalmology, MMC and RI, Mysore. \\ ${ }^{4}$ Assistant Professor, Department of Pathology, Melaka Manipal Medical College, Manipal University. \\ 5Junior Resident, Department of Ophthalmology, MMC and RI, Mysore. \\ 6Junior Resident, Department of Ophthalmology, MMC and RI, Mysore. \\ $7 J u n i o r$ Resident, Department of Ophthalmology, MMC and RI, Mysore. \\ $8 J u n i o r$ Resident, Department of Ophthalmology, MMC and RI, Mysore.
}

\begin{abstract}
BACKGROUND

Lesions of the lacrimal fossa and gland constitute about $5 \%-13 \%$ of all orbital masses confirmed by biopsy. The diagnosis, the histopathological correlation and treatment of lacrimal fossa lesions are important to ophthalmologists. The aim of this study is to analyse retrospectively 31 cases of lacrimal fossa lesions diagnosed over a 10 -year period.
\end{abstract}

\section{MATERIALS AND METHODS}

The clinical features and the histopathological features of 31 cases diagnosed as lacrimal fossa lesions between 2004 September and 2014 August were retrospectively analysed from case records in a tertiary care centre at Department of Ophthalmology, KR Hospital, MMC and RI, Mysore.

\section{RESULTS}

The present study includes 31 cases of lacrimal fossa lesions over a period of 10 years. The age of patients spanned from $5-74$ years. Among the total 31 cases, 15 (48.39\%) were male and 16 (51.61\%) were female. The most frequent primary epithelial tumour in benign was pleomorphic adenoma (19.35\%) and malignant epithelial tumours were adenocystic carcinoma (3.23\%), mucoepidermoid carcinoma (3.23\%) and carcinoma ex pleomorphic adenoma (3.23\%). Among the patients reviewed 38.71\% had inflammatory lacrimal gland lesions, $48.39 \%$ epithelial lesions and $12.9 \%$ lymphoproliferative lesions. The study included $90.32 \%$ benign lesions and $9.68 \%$ malignant lesions. According to the pathological origin of the lesions, they may be classified into $51.61 \%$ non-epithelial lesions and $48.39 \%$ epithelial lesions, 9.68\% malignant epithelial tumours, $19.35 \%$ benign epithelial tumours, $6.45 \%$ dacryops and dermoid $12.9 \%$.

\section{CONCLUSION}

Lacrimal fossa lesions show a wide pathological range. Inflammatory lesions are most frequent, followed by epithelial lesions. Analysis of clinical and radiological criteria is helpful in the differential diagnosis of lacrimal gland lesions.

\section{KEYWORDS}

Adenoid Cystic Carcinoma; Histopathology; Lacrimal Gland; Pleomorphic Adenoma; Tumour.

HOW TO CITE THIS ARTICLE: Krishnamurthy H, Devi MN, Venkategowda HT, et al. A clinicopathological study of lacrimal fossa

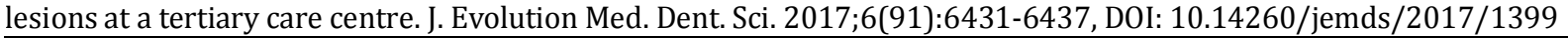

\section{BACKGROUND}

Lesions of the lacrimal fossa and gland constitute about $5 \%$ $13 \%$ of all orbital masses confirmed by biopsy.[1] The diagnosis, the histopathological correlation and treatment of lacrimal fossa lesions are important to ophthalmologists. A variety of inflammatory lesions and tumours can present within the lacrimal fossa. From the clinical series of the Wills Eye Hospital, lacrimal gland tumours represent almost 10\% of the mass occupying lesions in the orbit with inflammatory and lymphatic lesions accounting for $80 \%$ and epithelial

'Financial or Other Competing Interest': None.

Submission 07-10-2017, Peer Review 08-11-2017,

Acceptance 15-11-2017, Published 27-11-2017.

Corresponding Author:

Dr. Manjula Devi N,

\#904/12, Murthy Nilaya,

Nanju Mallige Circle,

Mysore-570004.

E-mail:dr.hemalatha_k@yahoo.in DOI: $10.14260 /$ jemds $/ 2017 / 1399$ lesions for $20 \%$ of the lacrimal fossa lesions. Among the epithelial lesions, $55 \%$ are benign and $45 \%$ are malignant.[2] There are four main groups of lacrimal gland lesions: Inflammatory, lymphoid, primary epithelial tumours and metastatic tumours.[3] Other less common lesions such as idiopathic orbital inflammation or developmental cysts may also occur in lacrimal fossa.[4] The reported incidences and types of lacrimal fossa lesions showed great variation in previously reported literature, mainly because of clinical data from different sources. Patients recruited from tertiary or primary ophthalmic care centres may have different spectrum of pathologies. Also because of varied different geographic areas. Age of patients also affect the relative frequency of lacrimal fossa lesions. For instance, in elderly adult malignant tumours are more common, comprising $63 \%$ of orbital tumours.[5,6] In India not many epidemiological surveys on lacrimal fossa lesions has been reported up to date. Patient may come with diplopia, protrusion of eyeball, squint, dry eyes and loss of vision. Confirming the diagnosis by correlating the clinical profile and radiological findings 
would guide the ophthalmologists in managing lacrimal fossa lesions. This study would provide data on the clinicopathological correlations of lacrimal fossa lesions in the south Indian population.

\section{MATERIALS AND METHODS}

In this case series, the medical records of 31 patients diagnosed with lacrimal fossa lesions from 2004 September to 2014 August were identified and collected throughout at the Department of Ophthalmology, KR Hospital, Mysore Medical College and Clinical Research, Mysore. Clinical examination findings in patients with lacrimal fossa lesions can include globe displacement (generally the eye is pushed downwards, inwards and forwards) and fullness in the superior-temporal aspect of orbit. Other signs and symptoms to look for include ptosis, fullness of upper lid laterally, erythema or engorged vessels of overlying skin, change in facial sensation, restricted motility and conjunctival changes. The duration of symptoms, type of onset, rapidity of progression, previous history of trauma or cancer history are important to elicit from the patient and a complete evaluation of all systems be taken. Further evaluation of these patients generally requires some imaging. CT scan and MRI are the most commonly performed investigations and provides important information about any possible changes in the adjacent bone. Immunohistochemical techniques were used in specific tumours. The management modalities including observation, excisional biopsy, incisional biopsy, enucleation, exenteration, radiotherapy, systemic corticosteroid and any combination of these treatments were assessed. Depending on the location of the lesion and size, either a lateral orbitotomy or a subbrow anterior approach was performed for tumour resection. The treatment outcome for patients followed up for 3 - 5 years, under observation for any recurrence or not, alive or dead were noted. The specimens were then sent to the Department of Pathology, MMC and RI, Mysore and the diagnosis was confirmed by histopathological experts.

\section{RESULTS}

There were 15 males (48.39\%) and 16 females (51.61\%). The age of patients diagnosed with lacrimal fossa lesions spanned from 5 years old to 74 years old. The mean age at the time of diagnosis was 51 years old. The most common initial presenting symptom was eyelid swelling, (26 patients, $87.5 \%$ ). The second most common symptom was proptosis ( 5 patients, 15.63\%). Amongst 31 patients diagnosed with lacrimal fossa lesion, most were benign (28 patients, 90.32\%) and only three patients $(9.68 \%)$ with malignant tumours were encountered and confirmed on histopathology. The most frequent primary epithelial tumour is pleomorphic adenoma in the benign (6 patients, 19.35\%) (Fig. 1), adenoid cystic carcinoma (1 patient, 3.23\%) (Fig. 2), pleomorphic adenocarcinoma (1 patient, 3.23\%) (Fig. 3) and mucoepidermoid carcinoma (1 patient, 3.23\%) (Fig. 4) in malignant group. Graph 1 shows various lesions of lacrimal fossa encountered in our present study.

\section{Pathological Profiles of Lacrimal Fossa Lesions in 31 Patients}

Using the pathological classification previously published by Shields et al,[2] lacrimal gland tumours were divided into two main types- epithelial (15 patients, 48.39\%) and nonepithelial lesions (16 patients, $51.61 \%$ ). The most common epithelial tumour was pleomorphic adenoma (6/31 patients, $19.35 \%$ ). Non-epithelial tumours were further subclassified into inflammatory lesions (12 patients, 38.71\%) and lymphoproliferative diseases (4 patients, 12.90\%). Inflammatory lesions consist of pseudotumours (6 patients, 19.35\%), dacryoadenitis (5 patients, 16.13\%) and granulomatous inflammation (1 patient, 3.23\%). Lymphoproliferative disease which include benign reactive lymphoid hyperplasia (4 patients, $12.90 \%$ ) and malignant lymphoma which were none in our series. The cases of dermoid cyst belong to 3 children 5 - 8 years of age and another in a teenager (4 patients, $12.90 \%$ ) and dacryops (2 patients, 6.45\%) all accounted for the lacrimal fossa lesions. The study included $90.32 \%$ benign lesions and $9.68 \%$ malignant lesions. Among the epithelial lesions, there were (20\% malignant epithelial tumours and $80 \%$ benign epithelial tumours). Table 1 shows different forms of lacrimal fossa lesions in the present study.

In all patients of lacrimal gland malignancy painful swelling was recorded, whereas a nontender palpable mass was detected in benign epithelial tumours. CT scan showed soft tissue lesion in extraconal aspect of orbit in superolateral region. Early detection and proper diagnosis of malignant lacrimal gland tumours influences the management, prognosis and survival of patients.
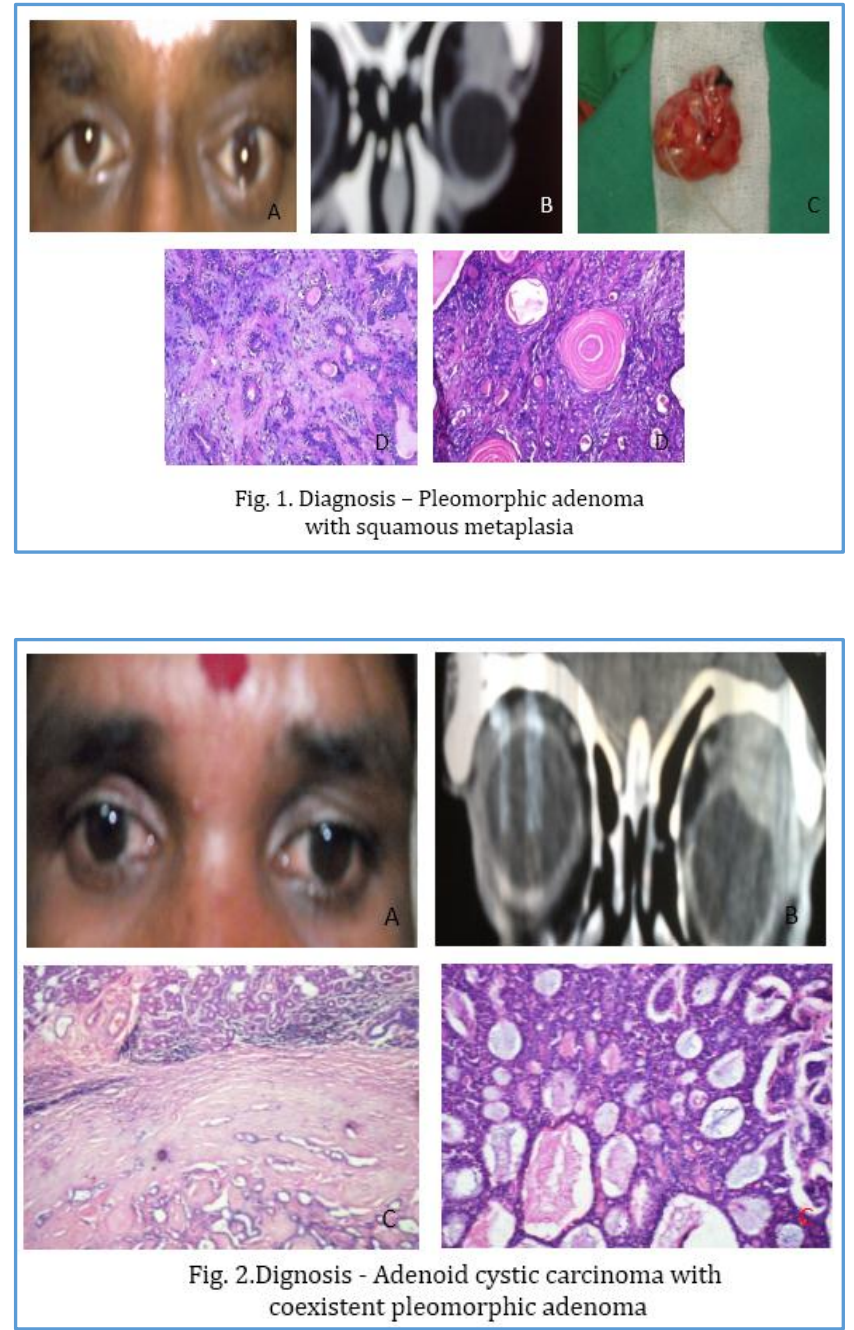


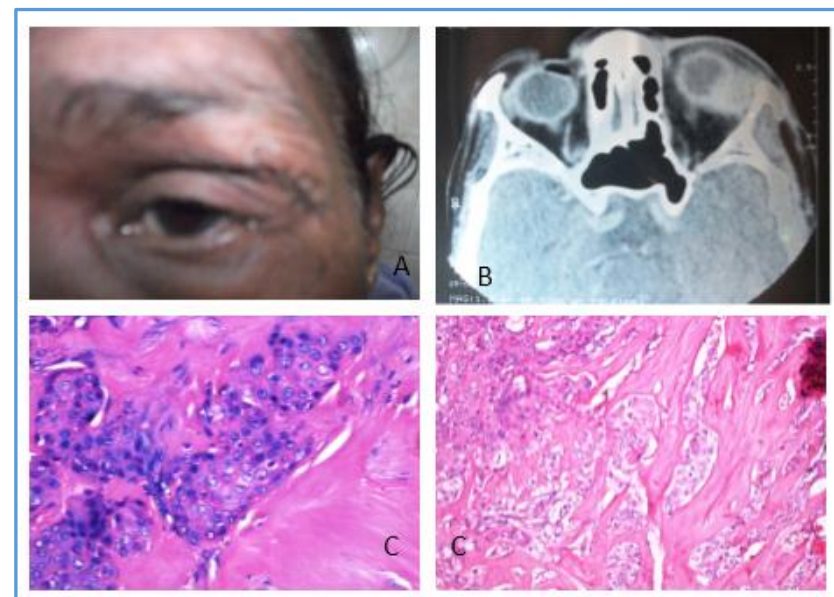

Fig. 3. Diagnosis - Recurrent pleomorphic adenoma carcinoma ex-pleomorphic adenoma

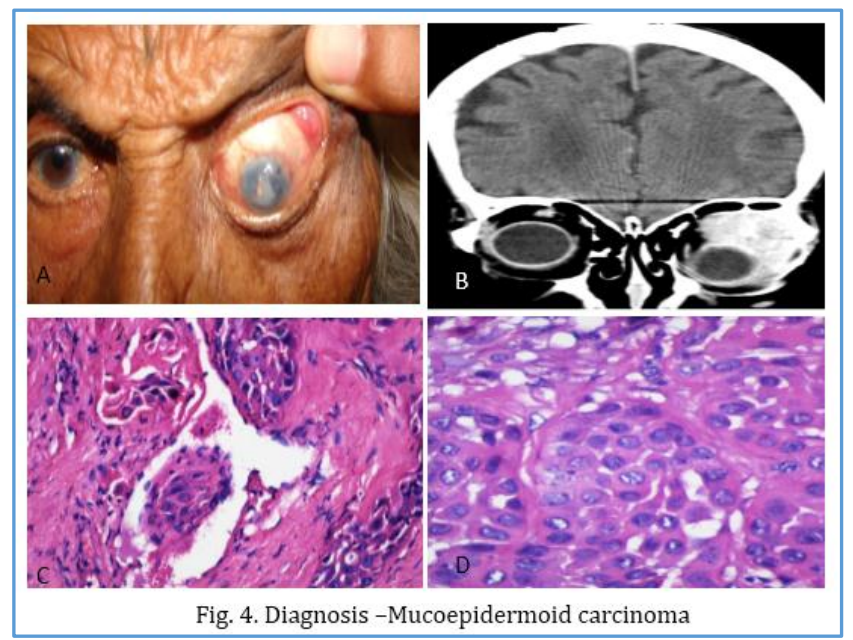

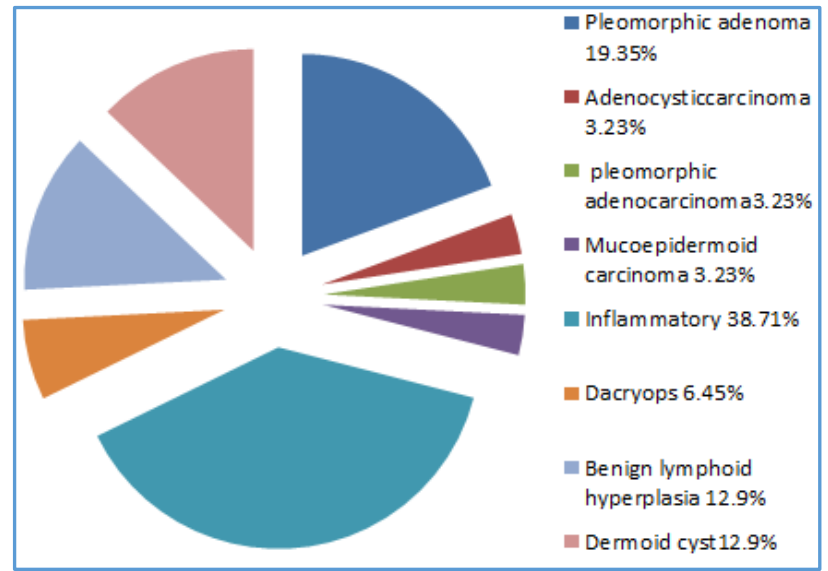

Graph 1. Shows various Lesions of Lacrimal Fossa Encountered in Our Present Study

\begin{tabular}{|cc|}
\hline Diagnosis & Number of patients (\%) \\
Inflammatory lesions & $12(38.71 \%)$ \\
Dacryoadenitis & $5(16.13 \%)$ \\
Idiopathic orbital inflammatory disease & $6(19.35 \%)$ \\
Granulomatous inflammation & $1(3.23 \%)$ \\
Lymphoproliferative & $4(12.90 \%)$ \\
& \\
Benign lymphoid hyperplasia & $4(12.9 \%)$ \\
& \\
Epithelial tumors & $15(48.39 \%)$ \\
Benign & $12(38.71 \%)$ \\
Benign-pleomorphic adenoma & $6(19.35 \%)$ \\
Dacryops & $2(6.45 \%)$ \\
Dermoid cyst & $4(12.9 \%)$ \\
Malignant & $3(9.38 \%)$ \\
Pleomorphic adenocarcinoma & $1(3.23 \%)$ \\
Adeno cystic carcinoma & $1(3.23 \%)$ \\
Mucoepidermoid carcinoma & $1(3.23 \%)$ \\
\end{tabular}

Table 1. Different Forms of Lacrimal Fossa Lesions in Our Study

\begin{tabular}{|c|c|c|c|c|c|c|c|c|c|}
\hline 冚 & 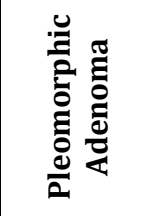 & 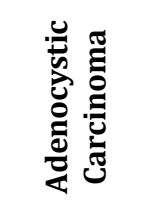 & 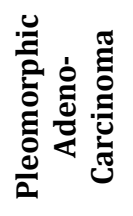 & 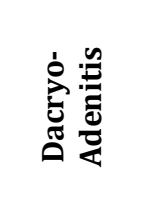 & 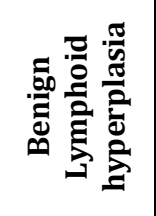 & 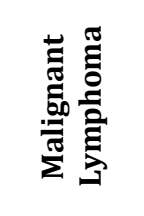 & & 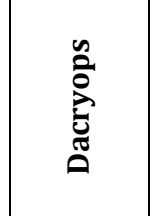 & 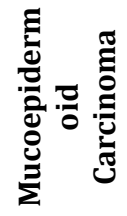 \\
\hline $\begin{array}{c}\text { Shields et al } \\
\text { (USA)[2] }\end{array}$ & $11(10 \%)$ & $14(12 \%)$ & $4(4 \%)$ & 37 (33\%) & $7(6 \%)$ & $16(14 \%)$ & $2 \%$ & $6 \%$ & $3 \%$ \\
\hline $\begin{array}{c}\text { Lee SB et al } \\
\text { (Singapore) })^{[10]}\end{array}$ & $\mathrm{n} / \mathrm{a}$ & $2(25 \%)$ & $1(13 \%)$ & $\mathrm{n} / \mathrm{a}$ & $\mathrm{n} / \mathrm{a}$ & $2(25 \%)$ & & & \\
\hline $\begin{array}{l}\text { Ohtsuka et al } \\
\text { (Japan)[8] }\end{array}$ & $21(24 \%)$ & $1(1 \%)$ & $6(7 \%)$ & $\mathrm{n} / \mathrm{a}$ & $16(19 \%)$ & $34(40 \%)$ & $(10.6 \%)$ & & \\
\hline $\begin{array}{c}\text { Ng DS et al } \\
\text { (Hong Kong) }{ }^{[5]}\end{array}$ & $5(22 \%)$ & $1(4 \%)$ & $\mathrm{n} / \mathrm{a}$ & $9(39 \%)$ & $3(13 \%)$ & $3(13 \%)$ & $1(4 \%)$ & & \\
\hline $\begin{array}{c}\text { Eldesouky } \\
\text { MA et al } \\
\text { (Egypt)[4] }\end{array}$ & $\begin{array}{c}11 \\
(7.53 \%)\end{array}$ & $\begin{array}{c}7 \\
(4.79 \%)\end{array}$ & $\begin{array}{c}6 \\
(4.11 \%)\end{array}$ & $\begin{array}{c}63 \\
(43.15 \%)\end{array}$ & $\begin{array}{c}11 \\
(7.53 \%)\end{array}$ & $\begin{array}{c}28 \\
(19 \%)\end{array}$ & $\begin{array}{c}8 \\
(5.48 \%)\end{array}$ & $8(5.48 \%)$ & \\
\hline $\begin{array}{l}\text { Present Study } \\
\text { (South India) }\end{array}$ & $\begin{array}{c}6 \\
(19.35 \%) \\
\end{array}$ & $\begin{array}{c}1 \\
(3.23 \%)\end{array}$ & $\begin{array}{c}1 \\
(3.23 \%) \\
\end{array}$ & $\begin{array}{c}5 \\
(16.13 \%) \\
\end{array}$ & $\begin{array}{c}4 \\
(12.9 \%) \\
\end{array}$ & nil & $\begin{array}{c}4 \\
(12.9 \%)\end{array}$ & $2(6.45 \%)$ & $\begin{array}{c}1 \\
(3.23 \%)\end{array}$ \\
\hline
\end{tabular}

\section{DISCUSSION}

There are various clinicopathological studies from different countries showing different types of lacrimal gland tumours including lacrimal fossa tumours in general population.[1-18]
Lacrimal fossa lesions are not common and consists of a wide range of pathologic lesions making its diagnosis and treatment challenging. Space occupying lesions of the lacrimal gland and its fossa constitute approximately $5 \%$ to 
$13 \%$ of orbital masses upon biopsy.[17] The largest clinicopathologic survey is reported by Shields et al[2] throughout a 30-year period. Of the 1264 patients with orbital tumour that were studied retrospectively, 114 (9\%) patients had lacrimal gland tumour; $45 \%$ were epithelial lesions and 55\% were non-epithelial lesions.[2] In our study among the reported epithelial lesions, $80 \%$ were benign and $20 \%$ malignant. This does not concord with the study by Shields et al in 2004, that states among the reported epithelial lesions $55 \%$ are benign and $45 \%$ are malignant. ${ }^{[2]}$ In Shields et al, series of 142 cases of lacrimal gland lesions showed $78 \%$ of lacrimal gland lesions were nonepithelial origin and only $22 \%$ were primary epithelial neoplasms. They reported 64\% inflammatory lesions, $14 \%$ lymphoid tumours, $22 \%$ lesion of epithelial origin (12\% pleomorphic adenoma, $6 \%$ dacryops and $4 \%$ malignant epithelial tumours).[1] In the present study we report $38.71 \%$ inflammatory lesions, $12.90 \%$ lymphoid tumours, $48.39 \%$ lesion of epithelial origin (19.35\% pleomorphic adenoma, 6.45\% dacryops and $9.68 \%$ malignant epithelial tumours). These results contradict the much quoted dictum that $50 \%$ of lacrimal gland lesions are primary epithelial tumours and $50 \%$ are nonepithelial lesions. Non-Hodgkin's B-cell lymphoma accounted for 16 cases (14\%) in Shields et al's series of 114 patients and is the most common malignancy in lacrimal gland lesions, especially in the elderly.[2] In our study according to the pathological origin of the lesions, $51.61 \%$ are nonepithelial lesions and $48.39 \%$ are epithelial lesions (among epithelial lesions 20\% malignant epithelial tumours, 53.33\% benign epithelial tumours and $26.67 \%$ dacryops) which is similar to the old dictum.

Ohtsuka et al published 244 orbital tumours, of which 86 patients had lacrimal gland lesions. They recorded $58.1 \%$ lymphoid lesions and $41.9 \%$ epithelial lesions $(24.4 \%$ pleomorphic adenoma, $10.6 \%$ dermoid cysts and $6.9 \%$ malignant epithelial tumours). They did not include lesions of inflammatory origin. ${ }^{[8]} \mathrm{Ng}$ et al reported $44 \%$ inflammatory lesions, $30 \%$ epithelial lesions $(22 \%$ pleomorphic adenoma, $4 \%$ adenoid cystic carcinoma and $4 \%$ dermoid cyst) and $26 \%$ lymphoid lesions.[5] These reports together with our study show that inflammatory lesions are the most common form of lacrimal fossa lesions followed by lymphoproliferative in other studies and epithelial lesions in our study with varying incidences.

From recent reports it suggests that inflammatory lesions and lymphoid tumours are more common than epithelial malignancies of the lacrimal gland which are considerably less frequent than commonly cited, ranging from $22 \%$ to $47 \% .[17]$ The Japanese even reported that the incidence of malignant lymphoma has increased from $5 \%$ to $15 \%$ over a decade.[14,18] Non-Hodgkin's B-cell lymphoma accounted for 16 cases (14\%) in Shields et al's[2] series of 114 patients and is the most common malignancy in lacrimal gland lesions, especially in the elderly. The high prevalence in Japan may be attributed to the improved sensitivity of immunohistochemical and molecular techniques, which help diagnosing low-grade B-cell lymphoma that might have been underdiagnosed as reactive lymphoid hyperplasia previously. Moreover, a recent study by Poso et al indicates that the incidence of malignant lymphoma is higher in Japan compared to Caucasian patients.[5,13] Infection with human Tlymphotropic virus type- 1 and even very aged atomic bomb survivors are claimed to be two regional factors in Japan. In this retrospective present study of 31 patients, epithelial lesions accounted for $48.39 \%$ of all the lesions of the lacrimal gland which concords with the study by Shields et al and Tse et al[2,17] and PA was the most common type of tumour. Similarly, the Lacrimal Gland Tumour Study Group in Japan also found that PA was the most common tumour of lacrimal fossa lesions.[14] $\mathrm{Ng}$ et al reported $44 \%$ inflammatory lesions, $30 \%$ epithelial lesions (22\% pleomorphic adenoma, $4 \%$ adenoid cystic carcinoma and $4 \%$ dermoid cyst) and $26 \%$ lymphoid lesions.[11] These reports, together with our study, show that inflammatory lesions (53.13\%) are the most common form of lacrimal gland lesions followed by epithelial lesions (48.39\%). Table 2 shows the incidences of lacrimal fossa lesions in six different series from various countries.

Information from the history, clinical examination and radiographic soft tissue contour analysis help to determine to which category of disease the lacrimal gland tumour belongsbenign epithelial tumour or malignant epithelial tumour, inflammation or lymphoproliferative disorder. Inflammatory disorders have acute presentation without contiguous bony changes. Insidious onset painless less than 1 year in an elderly age group with radiographic evidence of a lesion molding or conforming to ocular and bony contours rather than indenting adjacent structures are hallmarks of lymphoproliferative diseases. Subacute presentation of short duration usually 6 months and radiographic evidence of infiltration of adjacent structures, destruction or irregular erosion of bone and calcification are distinctive features of malignant epithelial tumours. Chronic presentation without pain associated with a radiographic finding of lacrimal fossa remodelling favours benign lacrimal gland tumours.[17]

Lacrimal gland inflammatory disorders are involved in a wide range of pathological processes. Acute dacryoadenitis could be either viral or bacterial and is usually unilateral. Patients present with symptoms and signs of inflammation, such as erythema and local tenderness. They rapidly respond to appropriate treatment. ${ }^{[4]}$ Chronic dacryoadenitis may follow acute infection or may be caused by tuberculosis, sarcoidosis, Graves' disease, Wegener's granulomatosis, Sjogren's syndrome or it may be idiopathic. Second most common site for idiopathic orbital inflammatory disease (IOID) is the lacrimal gland. On imaging, it is difficult to distinguish chronic dacryoadenitis from infiltrative tumours of the lacrimal gland. CT of these patients usually reveals mild-to-moderate oblong enlargement with moderate-tointense enhancement. The patients with IOID may show lateral rectus involvement with scleritis and fluid in the Tenon's capsule. ${ }^{[4,14]}$

Lacrimal gland lesions present special problems in diagnosis and management. Clinical recognition and differentiation of benign mixed cell lacrimal gland tumours from other neoplastic and inflammatory lesions of the lacrimal gland are feasible and should provide the basis for the approach to proper management.[15] Revised classification of lacrimal gland tumours and increased understanding has brought evolution to the nomenclature and new diagnostic and therapeutic modalities. To assess lacrimal gland lesions, CT and MRI are very valuable. A high index of clinical suspicion and knowledge of the radiologic findings and progression of the different lesions is imperative in managing with lacrimal tumours. Complete resection of the 
lacrimal gland may prevent recurrences and later malignant transformation of previously benign tumours. ${ }^{[4]}$ Rose et al proposed a diagnostic plan for diagnosis of persistent lacrimal gland masses, taking into account clinical and radiological criteria. They gave a score of -1 or +1 to each of the following criteria: Duration of symptoms (less or more than 10 months), persistent pain (present or absent), welldefined mass in radiology, molding of mass to the globe, tumour calcification and bone destruction. They stated that a total score of -8 to +2 favours the diagnosis of malignancy, while a score of +3 to +8 is probably a pleomorphic adenoma for total excision without prior biopsy.[19]

Lesions conforming to the clinical picture of benign mixed cell lacrimal gland tumours need not undergo incisional biopsy, but require en bloc excision with adjacent tissues through a lateral orbitotomy to ensure complete excision and to prevent late recurrence. Incisional biopsy is indicated and should not be delayed in suspected infectious and noninfectious inflammatory lesions that have not responded rapidly to medical therapy, and in other lesions suspected of being neoplastic and not amenable to total local excision.[15] Management of malignant tumours is still controversial and may require a more aggressive therapy including exenteration, en-bloc craniofacial orbitotomy with bone removal, radiotherapy and chemotherapy. ${ }^{[4]}$

Shields et al concluded that among benign lesions, the most common lacrimal gland tumours were pleomorphic adenomas and dacryops.[2] Pleomorphic adenomas accounts for 50 percent of all epithelial tumours of the lacrimal gland. Tumour becomes evident during the fourth and fifth decades as a slow onset ( $>12$ months) painless proptosis with inferonasal displacement of the globe.[1,15,20] All lacrimal gland pleomorphic adenomas should be excised along with pseudocapsule, since untreated or partially excised tumours carry a significant long-term risk of malignant transformation. ${ }^{[3,21]}$ The five-year recurrence rate is 3 percent for completely excised tumours and 32 percent for incompletely excised lesions. Previous studies reported a 10 percent incidence of malignant transformation of recurrent adenomas by 20 years after treatment and 20 percent by 30 years. [4]

The most common malignant epithelial tumour of the lacrimal gland is adenoid cystic carcinoma in many of the studies.[2,4,12] Shields et al concluded that among the malignant lesions ACC was the most common (66\%) followed by carcinoma ex pleomorphic adenoma (18\%), primary adenocarcinoma (9\%) and mucoepidermoid carcinoma (3\%).[2] ACC, age of presentation is about 40 years old, present with rapid onset $(<1$ year) of a painful temporal mass and tumour invades perineurally and into the adjacent bone (pain in 35\% to $40 \%$ cases).[22,23] ACC may present an advanced tumour with bone invasion.[12] The pain or tenderness was more in ACC compared to BMT, possibly owing to their aggressive behaviour and perineural invasion. ${ }^{[2,22]}$ On CT scans, ACC appears as round lesion with irregular borders within the lateral wall of the orbit with lacrimal fossa enlargement with bone invasion. Bita Esmaeli, MD and colleagues have recently shown that 50 percent of their patients with ACC had bone involvement.[24] Invasion of the tumour into the cavernous sinus, brain or bone marrow is best evaluated with an MRI with enhancement or contrast enhancement CT. [4]

Treatment for an adenoid cystic carcinoma is still controversial. Various surgical techniques include en bloc removal, local resection and exenteration. The tumour is difficult to dissect and radical exenteration with removal of the frontal bone, the lateral wall of the orbit and the temporal muscle has been recommended.[25] Even with this radical approach, 5 years is the mean survival with a 20-percent survival at 10 years. Mortality is associated with lung metastasis and intracranial invasion. $[1,5,20,22,23]$ Radiotherapy in the dose of 50 to $60 \mathrm{~Gy}$ after local resection has been demonstrated to prolong survival and reduce recurrences. ${ }^{[4]} \mathrm{A}$ new promising treatment option was published by David T Tse, MD, and colleagues on the use of intra-arterial cytoreductive chemotherapy (IAAC) as an adjunct to exenteration and standard radiotherapy. The authors found a significant reduction of recurrences and mortality related to the tumour with this treatment when compared with patients treated with conventional therapies.[26,27]

Shield JA et al has reported a women diagnosed of benign lacrimal gland mass at the age of 23 years, which turned malignant after 60 years and stated it to be malignant mixed tumour (pleomorphic adenocarcinoma) of the lacrimal gland.[28] We present a case of malignant transformation in a recurrence of the lacrimal gland tumour, 8 years after initial surgery. Some of the primary malignant epithelial tumours may arise from a pre-existing BMT through a malignant transformation- the so-called carcinoma ex pleomorphic adenoma (Ca ex PA), pleomorphic adenocarcinoma or malignant mixed tumour (MMT), but most arise de novo. ${ }^{[5]}$

We encountered a single case of mucoepidermoid carcinoma, the rare malignant epithelial tumour of the lacrimal gland. Shields et al has reported 3\% mucoepidermoid carcinoma and Alkatan HM et al have encountered a single case of this rare malignant epithelial tumour of the lacrimal gland.[2,12] Mucoepidermoid carcinomas is usually graded depending on the degree of differentiation and relative number of mucin-producing cells where lower grades have more mucin cells. The classification includes Grades 1 - 3 based on hyperchromatism, cellularity and frequency of mitotic figures. The most important prognostic indicator is the histopathologic grading.[12] Our case was graded histopathologically as Grade 3. After exenteration of orbit postoperatively patient had persistent neuralgic pain; however, no long-term followup was available for this patient.

In this study, $12.9 \%$ of patients had dermoid cysts. Dermoid and epidermoid cysts are a result of developmental sequestration of ectoderm within the suture lines of orbital bones. They arise from epithelial rests in the lacrimal fossa, but are not true lacrimal gland tumours. They may present at any age. The recorded age range is 10 - 91 years.[4,29] Dermoid cyst has similarly been reported $10.6 \%$ by Ohtsuka et al[8] which nearly concords with our study. A little less incidence of dermoid cyst $4 \%$ reported by $\mathrm{Ng}$ DS and $5.48 \%$ by Eldesouky MA et al has encountered in their study series and they do not concord to our study.[4]

Another epithelial lesions of the lacrimal gland include dacryops. Cyst of the lacrimal gland duct is termed dacryops and typically presents in young adults and middle-aged 
patients with female preponderance. Dacryops usually develops from the palpebral lobe of the lacrimal gland. It presents as a mass in the superotemporal conjunctival fornix, may develop spontaneously following an episode of dacryoadenitis or more rarely following conjunctival scarring or inflammatory conditions such as trauma, trachoma or ocular cicatricial pemphigoid. Dacryops accounted for 6 percent of cases in the 142 series of cases analysed by Shields CL et $\mathrm{al}^{,[1]}$ which is very much similar in our study as we have encountered $6.45 \%$ dacryops. In a recent clinical series of 1,264 consecutive patients with orbital tumours by Shields JA et al,[2] lacrimal gland lesions accounted for 114 (9 percent) and there were 19 cases of dacryops ( 2 percent of total) which does not concord to our study.

\section{CONCLUSION}

Appropriate management is vital and necessitates complete surgical resection of lacrimal fossa lesions under pathological conditions. Biopsy to be avoided on clinical and radiological suspicion of pleomorphic adenomas of the lacrimal gland thus prevent the recurrences and malignant transformation. Inflammatory lesions are most frequent, followed by epithelial lesions. Histopathological identification remains the only means for a correct diagnosis and plan for further treatment modalities.

\section{REFERENCES}

[1] Shields CL, Shields JA, Eagle RC, et al. Clinicopathologic review of 142 cases of lacrimal gland lesions. Ophthalmology 1989;96(4):431-5.

[2] Shields JA, Shields CL, Scartozzi R. Survey of 1264 patients with orbital tumors and simulating lesions: the 2002 Montgomery lecture, part 1. Ophthalmology 2004;111(5):997-1008.

[3] Font RL, Gamel JW. Epithelial tumors of the lacrimal gland: an analysis of 265 cases. In: Jakobiec FA, (eds). Ocular and adnexal tumors. Aesculapius: Birmingham, AL, 1978:787-805.

[4] Eldesouky MA, Elbakary MA, Sabik S, et al. Lacrimal fossa lesions: a review of 146 cases in Egypt. Clin Ophthalmol 2014;8:1603-9.

[5] Ng DS, Chan E, Yau K, et al. Clinicopathological survey of 23 patients with lacrimal fossa lesions in Hong Kong. Int J Ophthalmol 2011;4(3):311-3.

[6] Demirci H, Shields CL, Shields JA, et al. Orbital tumors in the older adult population. Ophthalmology 2002;109(2):243-8.

[7] Agarwal KR, Verma M, Menon S, et al. Profile of lacrimal gland lesions at a tertiary care centre. All India Ophthalmol Soc Proc 2006:389-91.

[8] Ohtsuka K, Hashimoto M, Suzuki Y. A review of 244 orbital tumors in Japanese patients during a 21-year period: origins and locations. Jpn J Ophthalmol 2005;49(1):49-55.

[9] Kohli M, Shah A, Bhatt S, et al. Lacrimal gland tumorsa retrospective histpathological study. Gujarat Medial Journal 2011;66(1):39-41.

[10] Lee SB, Au Eong KG, Saw SM, et al. Eye cancer incidence in Singapore. $\mathrm{Br} \mathrm{J}$ Ophthalmol 2000;84(7):767-70.
[11] Weis E, Rootman J, Joly TJ, et al. Epithelial lacrimal gland tumors: pathologic classification and current understanding. Arch Ophthalmol 2009;127(8):101628.

[12] Alkatan HM, Al-Harkan DH, Al-Mutlaq $\mathrm{M}$, et al. Epithelial lacrimal gland tumors: a comprehensive clinicopathologic review of 26 lesions with radiologic correlation. Saudi J Ophthalmol 2014;28(1):49-57.

[13] Poso MY, Mwanza JC, Kayembe DL. Malignant tumors of the eye and adnexa in Congo-Kinshasa. J Fr Ophthalmol 2000;23(4):327-32.

[14] Shikishima K, Kawai K, Kitahara K. Pathological evaluation of orbital tumours in Japan: analysis of a large case series and 1379 cases reported in the Japanese literature. Clin Exp Ophthalmol 2006;34(3):239-44.

[15] Stewart WB, Krohel GB, Wright JE. Lacrimal gland and fossa lesions: an approach to diagnosis and management. Ophthalmology 1979;86(5):886-95.

[16] Mafee MF, Edward DP, Koeller KK, et al. Lacrimal gland tumors and simulating lesions: clinicopathologic and MR imaging features. Radiol Clin North Am 1999;37(1):219-39.

[17] Tse DT, Neff AG, Onofrey CB. Recent developments in the evaluation and treatment of lacrimal gland tumors. Ophthalmol Clin North Am 2000;13(4):66381.

[18] Lacrimal Gland Tumor Study Group. An epidemiological survey of lacrimal fossa lesions in Japan: number of patients and their sex ratio by pathological diagnosis. Jpn J Ophthalmol 2005;49(5):343-8.

[19] Rose GE, Wright JE. Pleomorphic adenoma of the lacrimal gland. Br J Ophthalmol 1992;76(7):395-400.

[20] Duck Kim Y. Lacrimal gland tumors. In: Karcioglu ZA. Orbital tumors, diagnosis and treatment. New York: Springer, 2005:204-20.

[21] Rose GE. To crash or not to crash? Probability in the management of benign lacrimal gland tumours. Eye (Lond) 2009;23(8):1625-8.

[22] Wright JE, Rose GE, Garner A. Primary malignant neoplasms of the lacrimal gland. Br J Ophthalmol 1992;76(7):401-7.

[23] Font RL, Smith SL, Bryan RG. Malignant epithelial tumors of the lacrimal gland: a clinicopathologic study of 21 cases. Arch Ophthalmol 1998;116(5):613-6.

[24] Esmaeli B, Golio D, Kies M, et al. Surgical management of locally advanced adenoid cystic carcinoma of the lacrimal gland. Ophthal Plast Reconstr Surg 2006;22(5):366-70.

[25] Esmaeli B. Histologic status of the bony walls of the lacrimal gland fossa in adenoid cystic carcinoma of the lacrimal gland. Paper presented at: Annual Meeting of the American Association of Ophthalmic Pathologists; November 7, 2008; Atlanta, GA.

[26] Tse D. Clinical and microdissection genotyping analyses of the effect of intra-arterial cytoreductive chemotherapy in the treatment of lacrimal gland adenoid cystic carcinoma. Trans Am Ophthalmol Soc 2005;103:337-67. 
[27] Tse DT, Benedetto P, Dubovy S, et al. Clinical analysis of the effect on intraarterial cytoreductive chemotherapy in the treatment of lacrimal gland adenoid cystic carcinoma. Am J Ophthalmol 2006;141(1):44-53.
[28] Shields JA, Shields CL. Malignant transformation of presumed pleomorphic adenoma of lacrimal gland after 60 years. Arch Ophthalmol 1987;105(10): 1403-5.

[29] Smirniotopoulos JG, Chiechi MV. Teratomas, dermoids, and epidermoids of the head and neck. Radiographics 1995;15(6):1437-55. 